\title{
TRIATOMA INFESTANS COLONIZANDO EM DOMICHUIOS DA BAI- XADA FLUMINENSE, ESTADO DO RIO DE JANEIRO, BRASIL
}

\author{
Mário B. Aragão * e Sebastião A. Souza *
}

Nos municipios de Duque de Caxias e Nova Iguaçu, que fazem parte do Grande Rio de Janeiro, foram encontrados domicílios infestados pelo $\mathrm{T}$. infestans.

Em duas localidades do Municipio de Duque de Caxias (Amapá e Piranema) foram encontrados $\mathrm{T}$. infestans infectados por flagelados morfològicamente indistinguiveis do Trypanosoma cruzi, sendo de notar que alguns dêsses insetos foram coletados em uma casa em que os moradores nunca tinham estado em zona afetada pela doença de Chagas.

Os autores concluem que a infestaçấo deve ser recente e discutem o problema dêsse triatomineo estar proliferando num clima opôsto ao de sua área de dispersão e numa região onde os triatomineos silvestres, que penetram nos domicílios, não conseguem formar colônias.

Não são novios os rumores sôbre a existência de Triatoma infestans nos arredores do antigo Instituto de Malariologia, hoje Cidade dos Meninos, no Município de Duque de Caxias, onde, entre os anos de 1952 e 1954, foram realizadas experiências com casas experimentais infestadas com êsse triatomíneo $(7,8)$. Antes de nós, alguns pesquisadores, entre os quais Miguel A. Souza (Comunicação pessoal) fizeram pesquisas no local, porém com resultados pouco satisfatórios. O número de $T$. infestans coletados não autorizava afirmar que a espécie estava colonizando nos domicílios.

Tivemos o nosso interêsse despertado para o problema quando, em agôsto de 1970 , recebemos a notícia de que uma professôra de Amapá, no Município de Duque de Caxias, havia mandado para o an- tigo Serviço de Produtos Profiláticos uma caixa contendo barbeiros.

\section{MATERIAL E MÉTODOS}

Em virtude da finalidade do nosso trabalho ter sido descobrir e depois delimitar a área infestada, adotamos a seguinte rotina:

1 - Mostrar aos moradores T. infestans de diversos estádios, perguntando se conheciam o inseto;

2 - Aplicar pó insetífugo (Pirisa (Serviço de Produtos Profiláticos) nas casas em que os moradores informavam haver visto o barbeiro e coletar, durante 30 minutos, os insetos desalojados; 


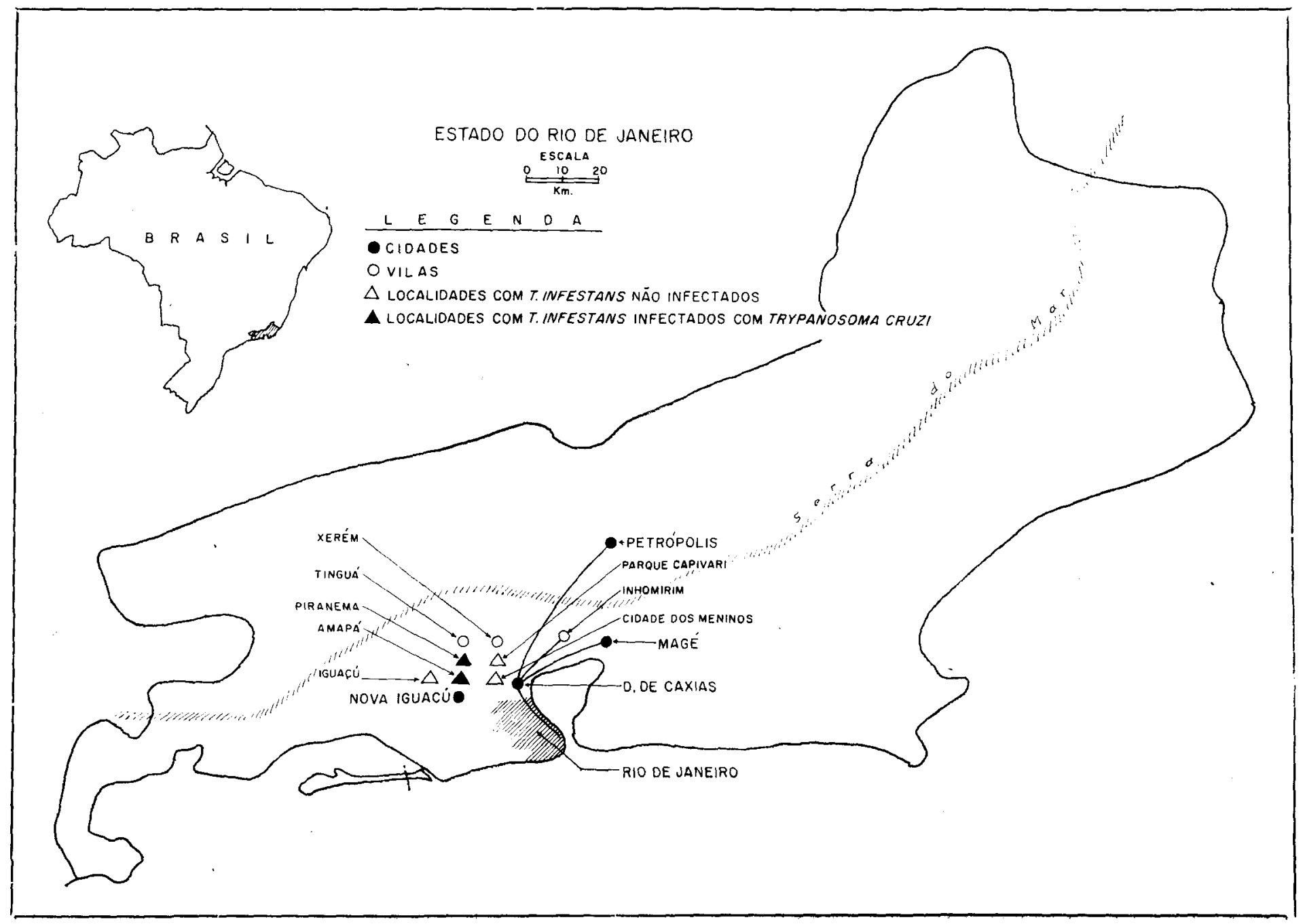

Figura 1 
3 - Examinar as fezes, obtidas por compressão do abdomem, de pelo menos $50 \mathrm{~T}$. infestans de cada localidade;

4 - Percorrer as estradas que, da base da Serra do Mar, demandam a periferia do Grande Rio de Janeiro, seguindo a rotina dos itens anteriores, com a finalidade de delimitar a área infestada.

\section{RESULTADOS}

O número de $T$. infestans coletados em cada uma das quatro localidades do $\mathrm{Mu}$ nicípio de Duque de Caxias (Tabela 1) é suficiente para mostrar que a espécie formou colônias nos domicílios. O caso da localidade de Iguaçu, pertencente ao $\mathrm{Mu}$ nicípio de Nova Iguaçu é, entretanto, duvidoso.

O número de casas negativas nāo foi registrado na tabela 1 porque, pràticamente, só foram pesquisadas casas em que os moradores conheciam o barbeiro e informavam estar sendo importunados.

No domicílio de Piranema onde foram capturados $64 T$. infestans, dos quais todos os adultos estavam positivos, residia uma família procedente dos arredores de Campina Grande, no Estado da Paraíba. $\mathrm{Na}$ outra casa, da mesma localidade, onde também foram encontrados barbeiros infectados, morava um casal vindo de Governador Portela, Municipio de Miguel Pereira, Estado do Rio de Janeiro, que nunca transitou por zona assolada pela doença de Chagas.

As localidades de Amapá, Piranema e Parque Capivari, se sucedem ao longo da estrada Caxias-Xerém, porém as casas positivas situam-se longe da rodovia. Na Cidade dos Meninos, que é atingida diretamente pela antiga Rio-Petrópolis, as moradias infestadas ficam nos confins da localidade. Sòmente em Iguaçu, a casa positiva situava-se à margem da estrada principal.

Com exceção das localidades citadas na tabela 1 , todos os povoados situados ao longo das estradas Nova Iguaçú-Tinguá, Caxias-Xerém, Caxias-Inhomirim e Caxias-Magé foram pesquisados com resultado negativo.

Infelizmente êsse trabalho de delimitação da área infestada não pôde ser por nós concluído, porque a diretoria do Ins- tituto de Endemias Rurais houve por bem entregar essa tarefa à Circunscrição Estado do Rio de Janeiro do antigo Departamento Nacional de Endemias Rurais.

\section{OBSERVAÇÕES GERAIS}

Em tôda a área infestada o $T$. infestans é bem conhecido e apesar das pessoas dizerem que êle apareceu há uns dois ou três anos, já possui a designação popular de "cascudo". Sempre fomos guiados para as áreas infestadas por pessoas encontradas na margem das estradas que nos indicavam a casa de conhecidos que se queixavam do inseto.

Em Amapá, algumas pessoas informaram que os barbeiros tinham aparecido depois que compraram esteiras num fabricante local. Uma pesquisa feita nessa casa, onde teciam e guardavam as esteiras, forneceu $74 T$. infestans.

Em quase tôdas as localidades observamos que, quando o insetífugo desalojava muitas baratas (em geral Periplaneta americana), apareciam poucos barbeiros $\mathrm{e}$ vice-versa. Tivemos a impressāo de que a pequena proliferação de baratas nas casas onde os barbeiros eram numerosos, decorria, principalmente, da miséria das famílias e, portanto, da pequenì quantidade de alimentos que ficava disponíveI para aquêles insetus. Por outro lado, ficou bem patente, em todo o decorrer das pesquisas, que as famílias que não estão no último degrau da miséria, conseguem se livrar dos triatomíneos ou, pelo menos, manter as suas populações em níveis muito baixos. Foram observadas medidas profiláticas de três tipos: abandono da casa e construção de uma nova moradia, revestimento das paredes e aplicação de inseticidas de uso doméstico ou agrícola. Devemos informar que essas medidas foram tomadas espontâneamente, pois nunca foi feita nessas localidades nenhuma campanha de educação sanitária, nem nenhum dos habitantes tinha conhecimento da existência da doença de Chagas.

A questão do status econômico, na área infestada, está ligada ao problema do transporte. Nos locais que podem ser atingidos por caminhāo $\mathrm{em}$ qualquer época, os moradores podem se dedicar a produtos mais valorizados, como hortaliças, ao passo que, onde os caminhos são piores, têm que ficar restritos a produtos não pe- 
T A B EL A 1

RESULTADO DE COLETAS DE TRIATOMINEOS REALIZADAS NA BAIXADA FLUMINENSE, ESTADO DO RIO DE JANEIRO, BRASIL, DE SETEMBRO A DEZEMBRO DE 1970, E DE ACHADOS DE TRIPANOSSOMOS DO TIPO CRUZI.

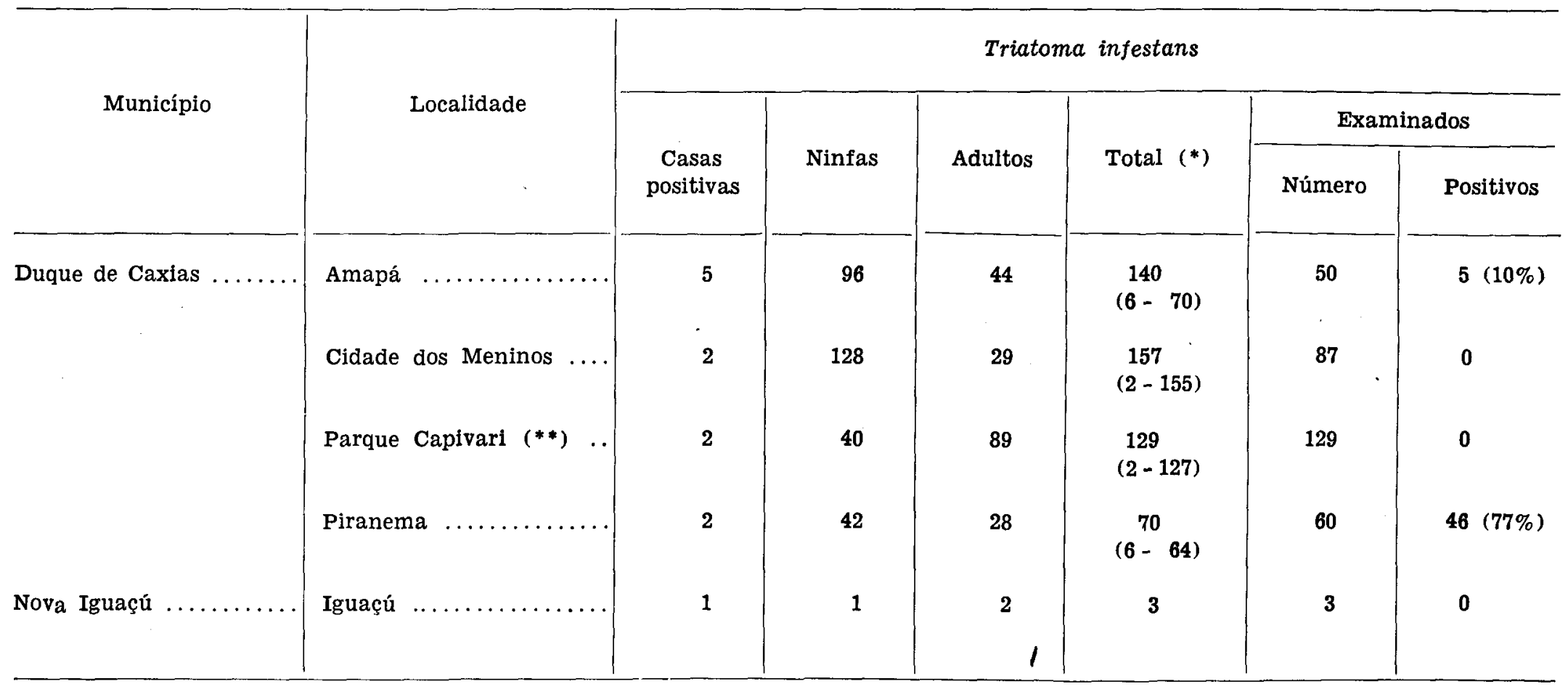

(*) Abalxo do total estão os números minimo e máximo, encontrados.

(*) Essa localidade também é conhecida por Penha do Caixāo. 
reciveis. A localidade mais pobre, que é a de Piranema, fica llhada na época das chuvas e nela quase só existem plantações de cana de açúcar e de mandioca, além de pequenos plantios de produtos de subsistência.

No Município de Nova Iguaçu, nos indicaram como infestada por barbeiros uma localidade chamada Barreira, habitada principalmente por operários de uma extràção mecanizada de areia. Em diversas casas os moradores reconheceram o triatomíneo e declararam tê-lo combatido com inseticida de uso doméstico. Em duas casas dessa localidade em que aplicamos pirisa, não observamos o desalojamento de inseto de qualquer espécie.

$\mathrm{Na}$ localidade de Iguaçú, a uns $10 \mathrm{me}-$ tros da casa em que foram coletados os barbeiros, o insetífugo desalojou uma colônia de formigas do gênero Camponotus (conhecidas localmente pela designação de formiga douceira) do interior de buracos de tijolos furados. A casa era construida de tijolos furados e tinha a parte interna da parede quebrada, em alguns pontos. Essas duas casas de Iguaçú foram as únicas que foram vistas sem o número da Campanha de Erradicação da Malária e, portanto, devem ter sido as únicas que nunca foram dedetizadas.

Alguns barbeiros infectados, colhidos em Amapá e Piranema, foram entregues ao Prof. José Rodrigues Coura-que estudou os flagelados, concluindo que eram indistinguíveis do Trypanosoma (Schizotrypanum) cruzi.

\section{DISCUSSÃO}

O fato dêsses focos de $T$. infestans serem de introdução recente parece fora de dúvida.

H verdade que nunca houve um trabaIho sistemático de procura de triatomíneos no Estado do Rio de Janeiro, porém na área em aprêço trabalharam diversos pesquisadores interessados nêsse grupo de insetos. No comêço do século, Carlos Chagas e Artur Neiva residiram no Xerém, durante a construção da adutora do mesmo nome. Na década de 1920 Henrique Aragão e Raul di Primio cuidaram da profilaxia da malária na antiga Fazenda de São Bento, que englobava a área da atual Cidade dos Meninos. No Instituto de Malariologia trabalhou Leônidas Deane e a equipe de entomologia chefiada por Renê Rachou. Por outro lado, as indagaçóes que fizemos na área não permitem concluir que a origem da infestação seja o Instituto de Malariologia. Os moradores da Cidade dos Meninos dizem que o inseto apareceu há uns cinco ou seis anos e os das demais localidades informam que notaram a presença do barbeiro de uns dois ou três anos para cá. Fica assim um hiato de 10 anos entre o término das experiências e o aparecimento dos triatomíneos nos domicílios. Deve-se ainda acrescentar que os moradores da área onde estão as instalações da Cidade dos Meninos nunca notaram a presença de barbeiros em suas casas, apesar de existirem umas poucas moradias de pau-a-pique.

Por outro lado, a introdução e não colonização do $T$. infestans, em zonas fora de sua área normal de dispersão, tem sido referida por vários pesquisadores: favelas do Rio de Janeiro (1), baixada litorânea do Estado de São Paulo (12), diversas localidades do interior de Pernambuco e Alagoas (4) e Montevideu, no Uruguai (5).

Colocam-se, portanto, dois problemas: 1) - a espécie estar proliferando num clima oposto ao de sua área normal de ocorrência - temperado e sêco; 2) - a espécie estar colonizando domicílios numa região onde triatomíneos que são domiciliares em outras áreas penetram acidentalmente nas casas, mas não formam colônias.

Quanto à primeira questão, poder-se-ia dizer que o inseto se desenvolve perfeitamente em estufa a mais de $30^{\circ} \mathrm{C}$. Já mantivemos $T$. infestans nessas condições $\mathrm{e}$ observamos que as ninfas crescem e fazem mudas perfeitamente, mas os adultos morrem em poucos dias. Há ainda o fato de existirem colônias da espécie em laboratórios do Rio de Janeiro. Os próprios barbeiros das experiências citadas $(7,8)$ foram trazidos de Minas Gerais e multiplicados até atingir alguns milhares, na Cidadé dos Meninos (6). Entretanto, o Dr. Herman Lent (Comunicação pessoal), que mantinha no Instituto Oswaldo Cruz uma colônia de $T$. infestans há 30 anos, informa que, aos poucos, os barbeiros vão ficando menos prolixos, sendo necessário, de tempos em tempos, introduzir exemplares trazidos do campo.

Com referência ao outro problema, isto 
é, a questão da área estudada pertencer a uma região onde os triatomíneos não colonizam nos domicílios, devemos informar que fato idêntico foì observado na Venezuela. Nêsse país, segundo o Dr. GomezNuñes (Comunicação pessoal) existe uma regiāo onde uma formiga impede a colonização dos domicílios pelo Rhodnius prolixus. Fato assemelhado toi referido por Perlowagora-Szumlewicz (7) que, nas experiências já citadas, apesar de manter as suas casas experimentais cercadas por uma mistura de sabão de breu e óleo diesel, na época mais quente do ano, não conseguiu evitar que as formigas destruissem barbeiros.

Freitas (3) cita vários autores que se referem ao fato do DDT provocar um "aumento da infestação das casas pelos triatomineos, por causa da destruição de seus inimigos naturais", porém concui que essa afirmativa "está baseada em informações muito vagas". Nós mesmos já tivemos ocasiāo de ouvir de pessoas do interior do país a queixa de que depois que passaram a aplicar o DDT nas casas, o número de barbeiros aumentou.

Esse é um assunto que deve ser estudado, porque na área infestada tôdas as casas tinham sido dedetizadas várias vêzes, em ciclos semestrais, e nelas não encontramos as formigas que tanto molestaram as colônias das casas experimentais da Cidade dos Meninos.

O fato dos barbeiros não terem colonizado nas casas da área situada do lado direito da Estrada Rio-Petrópolis (Figura 1) parece decorrer do melhor padrão de vida ai observado e que é uma decorrência da presença da refinaria e do conjunto petroquímico ai instaiados pela Petrobrás e de outras indústrias e serviços que a êles se seguiram. Ao longo das duas es- tradas representadas no mapa (CaxiasMagé e Caxiás-Inhomirim) as casas de pau-a-pique são uma raridade.

Fato semelhante foi observado no Estado de São Paulo, onde Reis et alii, (9) têm notado o desaparecimento do $T$. infestans de diversas localidades, o que atribuem, em parte, ao "desenvolvimento sócio-econômico da região".

No foco de $T$. infestans ora estudado, a ligação entre doença de Chagas e miséria se apresenta de uma forma que poderíamos classificar de didática. A área mais infestada, pertencente ao INCRA (Instituto Nacional de Colonização e Reforma Agrária) é constituída por terras ocupadas por posseiros sem situação legal definida que, devido à questão do transporte, não podem melhorar a sua situação financeira, nem tão pouco transferir os seus direitos a pessoas de melhor padrão de vida. Ao redor dessa área situa-se uma zona em que é possivel cultivar produtos mais valorizados $e$ onde a infestação é semi-controlada pelos moradores. Circundando essas duas áreas, encontra-se uma extensa faixa em que predomina uma população de empregados na indústria e no comércio e onde, em poucos lugares onde o $T$. infestans foi introduzido, foi exterminado pelos próprios moradores.

A questão do $T$. infestans estar restrito a uma área de alta miserabilidade, rodeada por um cinturão próspero, não deve ser motivo para que se retarde a sua erradicação. Deve ter-se em conta que a baixada do Sudeste Brasileiro é o império da miséria e, se a espécie sofreu qualquer adaptação que esteja permitindo que ela prospere em clima quente e úmido, poderá ser acidentalmente transportada e se dispersar por extensos áreas, atualmente jsentas de triatomíneos domiciliares.

\section{SUMMARY}

In the municipalites of Duque de Caxias and Nova Iguaçu. which are a part of the Greater Rio de Janeiro, dwellings were found infested by $\mathbf{T}$. infestans.

$\mathrm{T}$. infestans infected by flagellates morphologically indistinguishable from Trypanosoma (S) cruzi were found in two localities in the municipality of Duque de Caxias (Amapá and Piranema).

It was noted that some of these insects were collected in a house in which the dwellers have never been in a zone affected by Chagas' disease.

The authors conclude that the infestation is probably recent and discuss the problem of this Triatoma prolifering in a climate opposite to its area of dispersion and in a region where sylvan triatoma, which penetrates into the dwellings, is not able to form colonies. 


\section{BIBLIOGRAFIA}

1. ARAGÃO, M. B. \& DIAS, E. - Aspectos climáticos da doença de Chagas. I - Considerações sôbre a distribuição geográfica do Triatoma infestans. Rev. Bras. Malar. D. Trop., 8: 633-641, 1956.

2. CORREA, R. R. - Informe sôbre a doença de Chagas no Brasil e em especial no Estado de São Paulo. Rev. Bras. Malar, e D. Trop., 20: 39-81, 1968 .

3. FREITAS, J. L. P. - Profilaxia da moléstia de Chagas, in Doença de Chagas, pp. 541-559, editado por $\mathrm{J}$. Romeu Cançado, Imprensa Oficial do Estado de Minas Gerais, Belo Horizonte, 1968.

4. LUCENA, D. T. - Estudos sôbre a doença de Chagas no nordeste do Brasil. Rev. Bras. de Malar. D. Trop., 22: $3-173,1970$.

5. OSIMANI, J. J. - Enfermedad de Chagas: importante flagelo de las zonas rurales del Uruguay. Rev. Goiana Med., 5: 339-356, 1959.
6. PERLOWAGORA - SZUMIIEWICZ A - Ciclo evolutivo do Triatoma infestans em condições de laboratório. Rev. Bras. Malar. D. Trop., 5: 35-47, 1953 .

7. PERLOWAGORA - SZUMLEWICZ A - A eficácia do expurgo domiciliar com hexaclorociclohexana no contrôle do vetor da doença de Chagas (importância de alguns caracteristicos biológicos dos triatomíneos no planejamento do ciclo de aplicação do inseticida). Rev. Bras. Malar. D. Trop., 6: 63-100, 1954.

8. PERLOWAGORA - SZUMLEWICZ, A. - A eficácia do expurgo domiciliário com dieldrin no contrôle do vetor da doença de Chagas. Rev. Bras. Malar. D. Trop., 8: 289-304, 1956 .

9. REIS, U. L., FRANÇA, J. B. M. \& SILVA, E. Ó. R. - Úm critério de menor custo como subsídio para a escolha do método de combate a triatomíneos vetores da doença de Chagas. Rev. Saúde públ., 3: 31-39, 1969. 